\title{
Clinical aspects, management and outcome of brain arteriovenous malformations - results with microsurgery first policy
}

\author{
Aurelia Mihaela Sandu ${ }^{1,2}$, Vasile Gheorghe Ciubotaru', \\ Ligia Gabriela Tataranu ${ }^{2,3}$, Alexandru Tascu ${ }^{2,3}$, Narcisa Bucur ${ }^{2}$, \\ Angela Neacsu $^{2}$, Mircea Radu Gorgan ${ }^{2,3}$ \\ ${ }^{1} \mathrm{PhD}$ student, University of Medicine and Pharmacy "Carol Davila”, Bucharest \\ ${ }^{2}$ Clinic of Neurosurgery, Emergency Clinical Hospital "Bagdasar Arseni”, Bucharest \\ ${ }^{3}$ University of Medicine and Pharmacy "Carol Davila", Bucharest
}

\begin{abstract}
We performed a retrospective study, including patients operated for brain AVMs between 1999 and 2014, in the Clinic of Neurosurgery, Emergency Clinical Hospital Bagdasar-Arseni, Bucharest. 277 patients underwent surgery for brain AVMs. Mean age was 29.82 years. 195 patients (70.40\%) presented with hemorrhage and 86 cases (31.05\%) were admitted with seizures. We performed total resection of AVMs in 228 cases (82.31\%) and subtotal resection in 49 cases (17.69\%). Regarding patients with residual nidus, 16 of them underwent second surgery, 27 stereotactic radiosurgery Gamma Knife, 3 embolization and 3 refused further treatment. Modified Rankin Scale (mRS) improved following surgery $(Z=-9.248, p=0.000)$. Early complications $(0-30$ days $)$ were encountered in 84 patients (30.32\%). We found the following risk factors for postoperative complications occurrence: motor deficit $(\mathrm{p}=0.006)$, co-morbidities $(\mathrm{p}=0.023)$, higher $\mathrm{mRS}(\mathrm{p}=0.005)$, lower Karnofsky score $(\mathrm{p}=0.003)$, lower GCS $(\mathrm{p}=0.016)$, profound nidus $(\mathrm{p}=0.001)$, eloquent aria $(\mathrm{p}=0.000)$, large nidus $(\mathrm{p}=0.000)$, multiple arterial territory $(\mathrm{p}$ $=0.000)$, deep feeding arteries $(\mathrm{p}=0.000)$, higher number of feeding arteries $(\mathrm{p}=0.000)$, deep venous drainage $(p=0.000)$, multiple draining veins $(p=0.000)$, higher SpetzlerMartin grade $(\mathrm{p}=0.006)$, high flow $(\mathrm{p}=0.000)$, vascular steel $(\mathrm{p}=0.000)$, associated aneurysms $(\mathrm{p}=0.010)$ and decompressive craniectomy $(\mathrm{p}=0.019)$. Mortality was $6.1 \%$. Microsurgery is the treatment of choice for brain AVMs. Surgical results are excellent, with low morbidity and mortality. Patients with poor surgical results belonged to the group admitted with severe altered general state, state of consciousness, massive hematomas and acute brainstem dysfunction. If part of the nidus cannot be safely surgical resected, stereotactic radiosurgery can provide definitive cure of the lesion.
\end{abstract}

Key words: arteriovenous malformations, microsurgery, postoperative complications. 


\section{Introduction}

Brain arteriovenous malformations (AVMs) are congenital complex network formed by dysplastic vessels (dilated arteries and enlarged arterialized veins interconnected by shunts), in which oxygenized blood flows from arteries directly into draining veins without passing through capillary bed. This network of vessels, called nidus, contains no brain tissue within.

Brain AVMs are rarely encountered, having a prevalence of $0.14 \%$. (12) Less than 1.5 new cases $/ 100,000$ inhabitants are reported each year.(1, 9, 37, 38) AVMs represent around $6 \%$ of all brain lesions. Usually are solitary, but in $2 \%$ of the cases can be multiple.

Brain AVMs become clinically manifest in young people, mean age at diagnosis being 33 years. (27) Brain AVMs have high mortality and morbidity rates. Brain AVMs represent the most frequent cause of spontaneous cerebral hemorrhage in young adults. Onset with intracerebral bleeding is found in $50 \%$ of brain AVMs. $(5,12)$ Cerebral hemorrhage is a major cause of mortality, morbidity and persistent neurological deficits. Following AVMs rupture, mortality reaches $10 \%$ and morbidity accounts for $30-50 \%$. $(12,15,17)$ Brain AVMs can manifest with seizures or long-term neurological deficits.

The aim of this study is to analyze clinical aspects, management and short and long-term outcome of brain AVMs, who underwent surgery, over a period of time of 15 years, using microsurgery first policy.

\section{Material and methods}

\section{Patient population}

We performed a retrospective study, including patients who underwent surgery for brain AVMs between 1999 and 2014, in the Clinic of Neurosurgery, Emergency Clinical Hospital Bagdasar-Arseni, from Bucharest. We excluded patients who were not operated, grade VI Spetzler-Martin AVMs, spinal AVMs and patients lost at follow-up. Follow-up period varied from 3 months to 15 years.

We reviewed medical records, and we recorded: demographic data, history, previous treatment, signs and symptoms at admission, general exam, neurological exam, modified Rankin score (mRS), Karnofsky score, GCS, cerebral CT scan, MRI, angio-CT, angio-MR, four/six vessel angiography, fundoscopy, EEG, surgical details, complications, early and late outcome, complications, other treatments, and prognosis. On follow-up patients were evaluated using all or some of the followings: general exam, neurological exam, cerebral CT, MRI, four vessels angiography, fundoscopy and EEG.

\section{Statistical analysis}

We used IBM $^{\otimes}$ SPSS $^{\oplus}$ Statistics 20 for statistical analysis. We performed uni- and bivariate analysis.

\section{Results}

From 1999 to June 2014, in the Clinic of Neurosurgery a total number of 820 patients were admitted with brain AVMs, but only 277 patients (33.78\%) underwent surgery. 


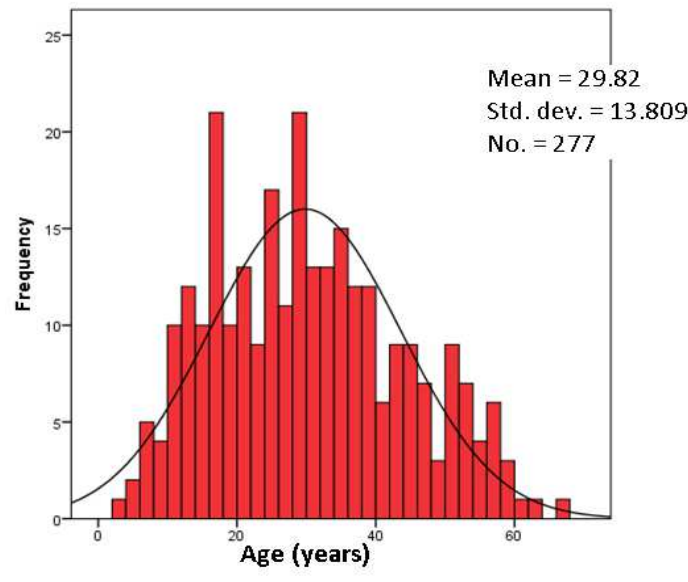

Figure 1 - Histogram for age distribution

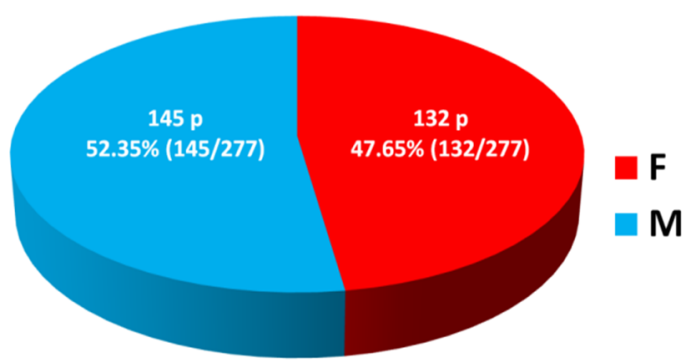

Figure 2 - Sex distribution

Age varied from 3 to 67 years (mean age 29.82 years, median age 29 years). Sex ratio was 1.098 .

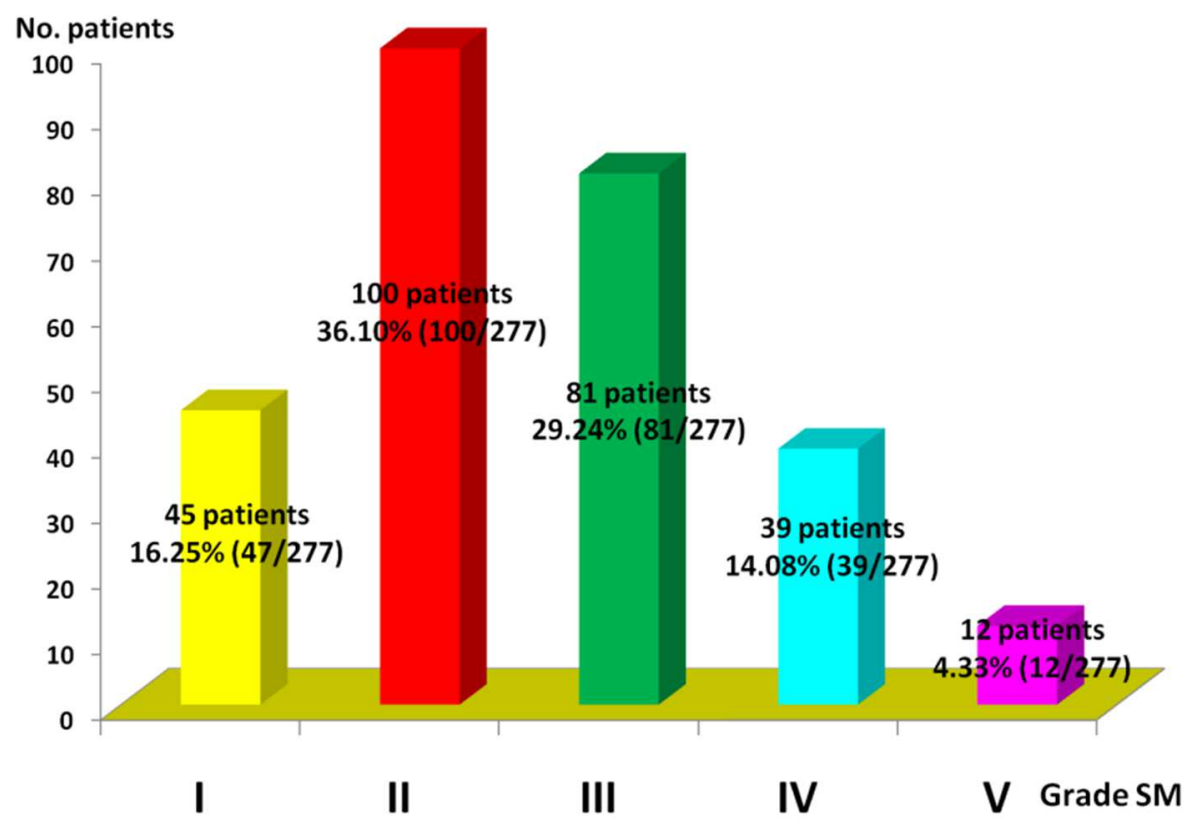

Figure 3 - Distribution according to Spetzler-Martin grading system 


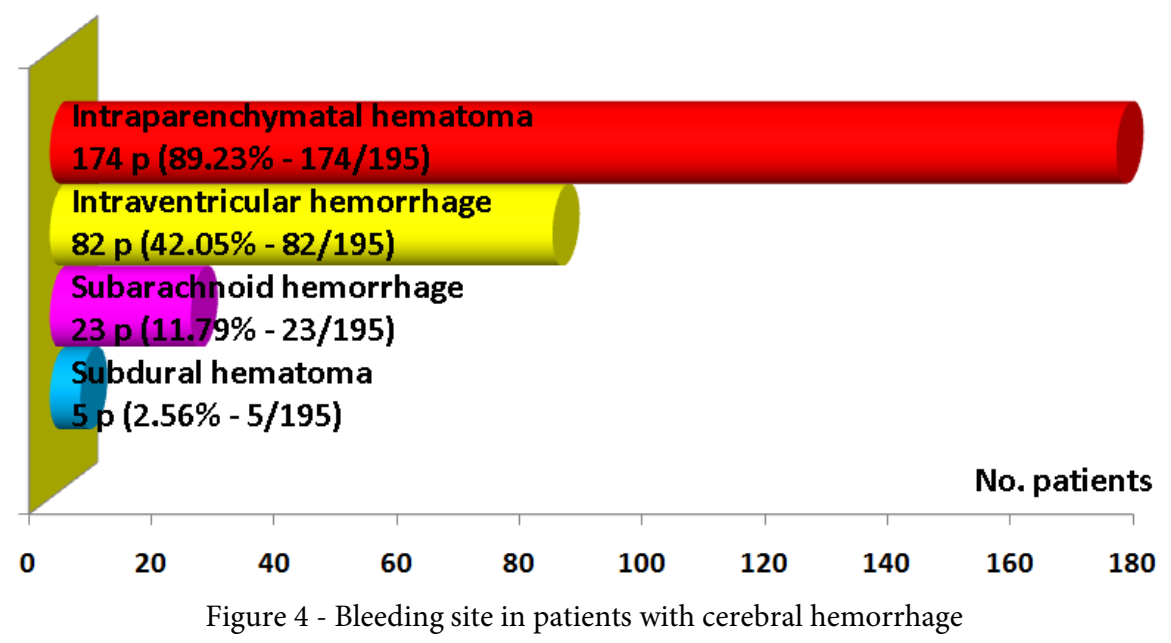

According to Spetzler-Martin grade, we found 45 patients (16.25\%) with grade I, 100 patients $(36.10 \%)$ with grade II, 81 patients (29.24\%) with grade III, 39 patients (14.08\%) with grade IV and 12 patients $(4.33 \%)$ with grade $\mathrm{V}$.

The two main pattern of AVMs presentation were onset with hemorrhage or seizures. In our series of patients 195 cases (70.40\%) presented with cerebral hemorrhage and $86(31.05 \%)$ were admitted with seizures. Analyzing only the group with hemorrhage, we found that 174 patients $(89.23 \%)$ had intraparenchymatal hematoma, 82 cases (42.05\%) presented intraventricular bleeding, 23 cases (11.79\%) had subarachnoid hemorrhage and 5 patients $(2.56 \%)$ had subdural hematoma.

Altered mental state was encountered in 115 patients (41.52\%). All patients presented with altered mental state came from the group with cerebral hemorrhage. One hundred eleven patients (40.07\%) presented motor deficits.
According to location, most of brain AVMs were found in the supratentorial compartment, 250 cases (90.25\%), compare with 27 cases $(9.75 \%)$ with infratentorial lesions. In 169 AVMs (61.01\%) the whole nidus or part of it was located in eloquent areas and in the rest of 108 cases (38.99\%) the nidus was seated in noneloquent areas. AVMs were superficial in 230 cases (83.03\%) and deep in 47 patients (16.97\%).

We recorded data regarding feeding arteries and venous drainage. In 209 cases (75.45\%) arterial supply came exclusively from superficial feeding arteries and in 68 malformations $(24.55 \%)$ from deep feeding arteries. Deep arterial feeders were represented by all feeding arteries coming from perforating or choroidal arteries. Feeding arteries came from a single arterial territory in 156 cases (56.32\%) and in 121 lesions (43.68\%) from multiple arterial territories. An arterial territory was represented by all branches arising from one major cerebral artery. 
DOI: 10.2478/romneu-2014-0053

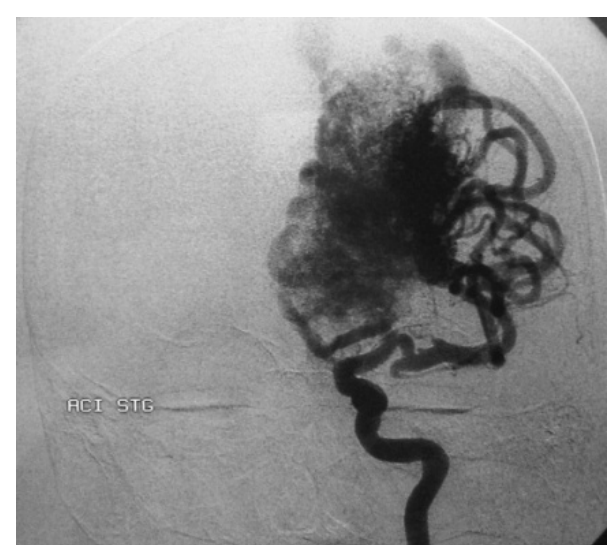

A

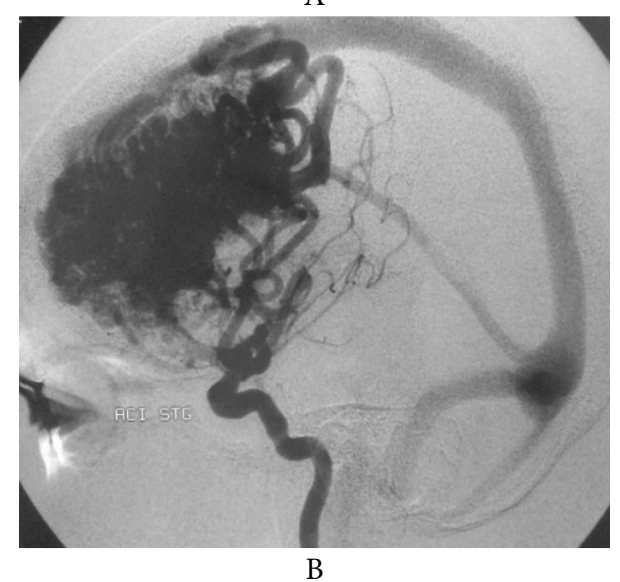

Anterior circulation territories were represented by ACA and MCA territories and posterior circulation territories were PCA, PICA, AICA and SCA territories. One hundred and sixty-eight AVMs (60.65\%) had only superficial venous drainage, while 109 (39.35\%) had deep venous drainage. One hundred thirty-four lesions (48.38\%) had a single draining vein and 143 cases (51.62\%) had multiple draining veins. Vascular steel was noted in 118 cases (42.60\%). Thirty two patients $(11.55 \%)$ also had one or multiple intracranial aneurysms.

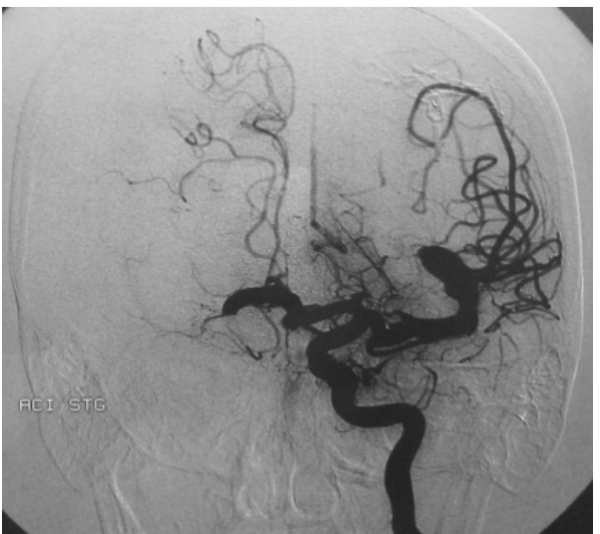

C

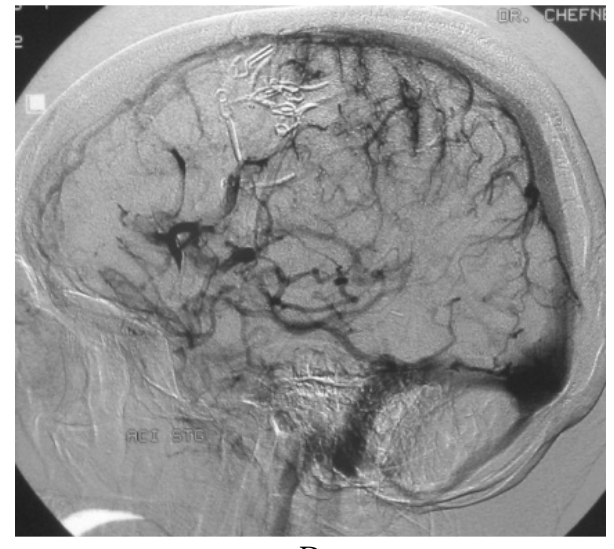

D

Figure 5 A, B - Giant left frontal AVM, feeding arteries from left MCA, left ACA, right ACA, left PCoA and left PCA. Venous drainage in straight sinus via SSS and SSI; C, D. Postoperative aspects: complete resection

We performed total resection of AVMs in 228 cases $(82.31 \%)$. The rest of 49 patients (17.69\%) had residual nidus. In patients with grade I Spetzler-Martin we were able to performed total resection in all 45 cases (100\%). In patients with grade II, we were able to achieve total resection in 93 cases (93\%) and we left a residual nidus in 7 patients (7\%). In grade III we performed total resection in 59 patients (72.94\%) and subtotal resection in 22 
cases $(27.16 \%)$. From the total number of cases with grade IV, we were able to perform 21 total resections (53.85\%) and 18 subtotal resections (46.15\%). In grade $\mathrm{V}$ we succeeded total resection in 10 cases $(83.33 \%)$ and in the other 2 cases $(16.67 \%)$ we left a residual nidus.

Regarding patients with residual nidus, 16 of them underwent second surgery, 27 stereotactic radiosurgery Gamma Knife, 3 endovascular embolization and 3 refused further treatment.

Decompressive craniectomy was performed in 70 cases (25.30\%).

We compared modified Rankin Scale (mRS) before and following surgery, and we found that in 202 patients $(72.92 \%) \mathrm{mRS}$ improved, in 41 cases $(14.80 \%)$ it remained unchanged and in 34 patients (12.28\%) mRS got worse. Statistical analysis, using Wilcoxon test, showed that mRS improved after surgery statistically significant $(Z=-9.248, \mathrm{p}=0.000)$.

Early complications (0-30 days) were encountered in 84 patients, leading to a morbidity rate of $30.32 \%$. Normal perfusion pressure breakthrough was noted in 17 cases (6.14\%). Secondary intraparenchymatal hematoma required emergent surgery in 16 cases and in one case it was limited, with no mass effect, the patient presented no additional neurological deficits and it was treated conservatively with good outcome.

TABLE 1

Early complications (0-30 days following surgery)

\begin{tabular}{|lcc|}
\hline Complications & No. patients & \% complications \\
\hline IPH $\leftarrow$ NPPB & 17 & $6.14 \%$ \\
\hline IPH $\leftarrow$ rebleeding from residual nidus & 2 & $0.72 \%$ \\
\hline Malignant brain swelling & 3 & $1.08 \%$ \\
\hline Ischemia & 2 & $0.72 \%$ \\
\hline Acute brainstem dysfunction & 6 & $2.17 \%$ \\
\hline EDH & 2 & $0.72 \%$ \\
\hline SDH, subdural hygroma & 3 & $1.08 \%$ \\
\hline Infections & 8 & $2.89 \%$ \\
\hline Seizures & 17 & $6.14 \%$ \\
\hline Hydrocephalus & 12 & $4.33 \%$ \\
\hline CSF fistula & 2 & $0.72 \%$ \\
\hline Arachnoiditis & 2 & $0.72 \%$ \\
\hline Motor deficit & 21 & $7.58 \%$ \\
\hline Aphasia/dysphasia & 7 & $2.53 \%$ \\
\hline Other neurological deficits & 5 & $1.80 \%$ \\
\hline Pulmonary complications & 5 & $1.80 \%$ \\
\hline Thrombocytopenia, coagulopathy, DIC & 1 & $0.36 \%$ \\
\hline Wound dehiscence & 1 & $0.36 \%$ \\
\hline
\end{tabular}

${ }^{\star}$ one patient may present more than one complication 
DOI: 10.2478/romneu-2014-0053

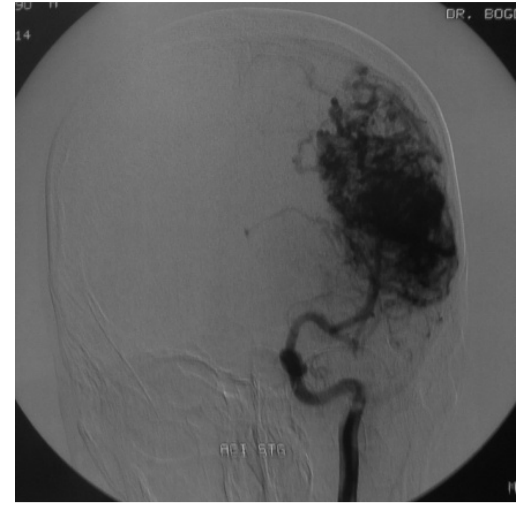

A

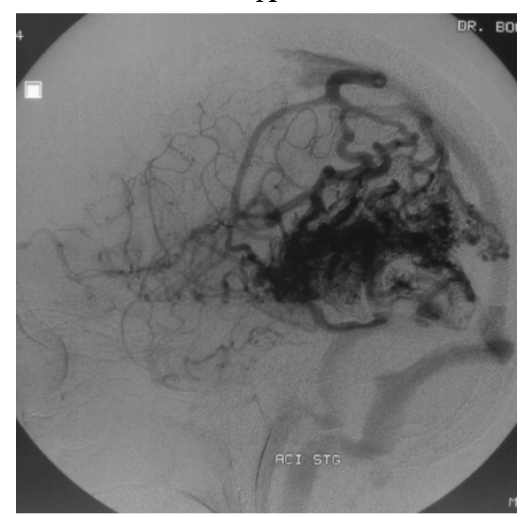

B

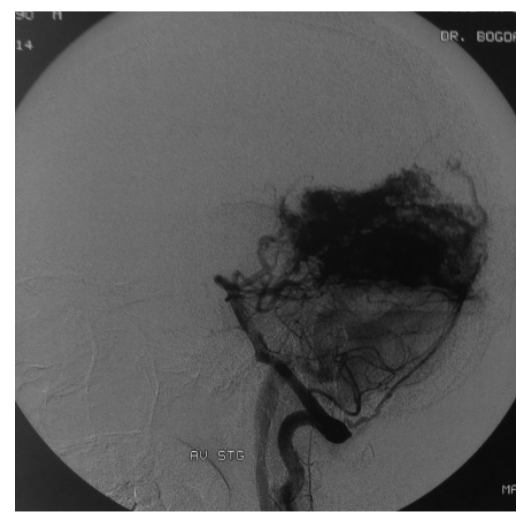

C

Figure 6 A, B, C - Giant left TPO AVM, feeding arteries from left MCA, left pericallosal artery, left PCA (P3 segment), left middle meningeal artery, left posterior meningeal artery, both occipital arteries.

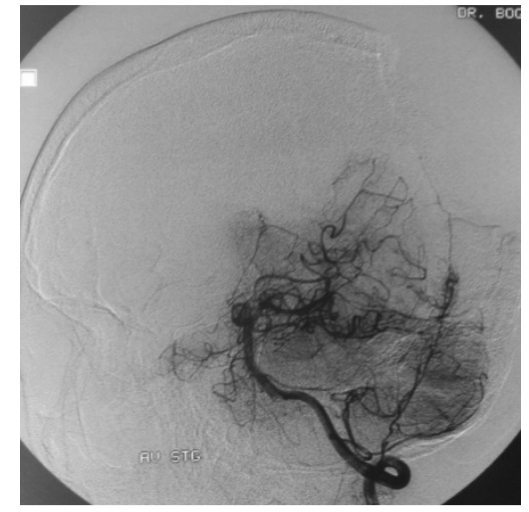

$\mathrm{D}$

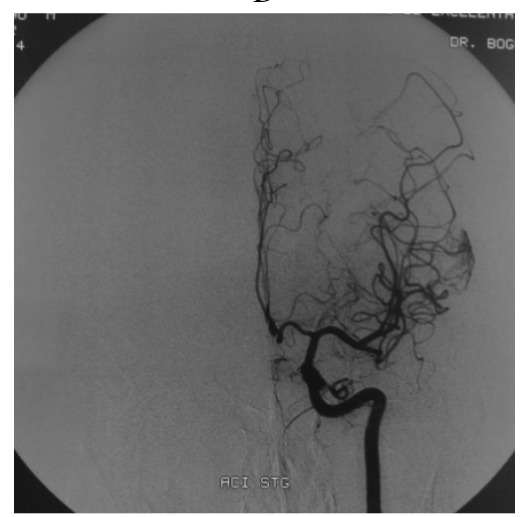

E

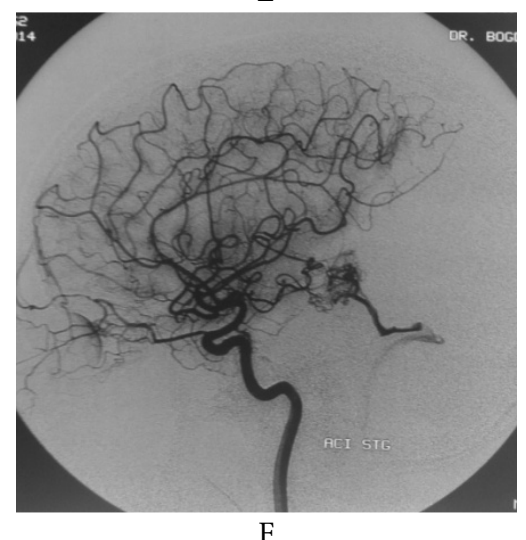

Venous drainage in SSS, left transverse sinus, herophili torcula and straight sinus;

D. E. F - Postoperative aspects: complete resection 


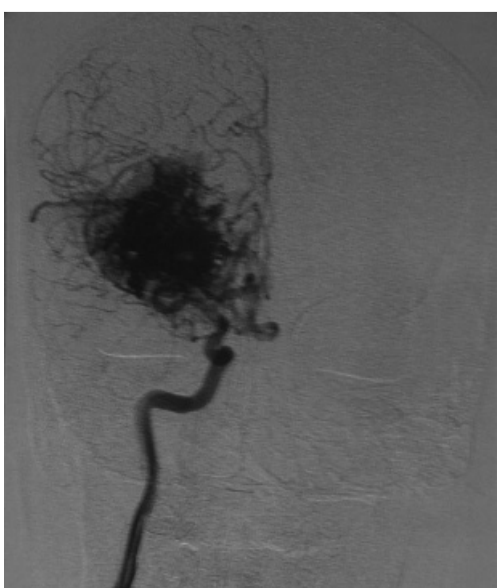

A

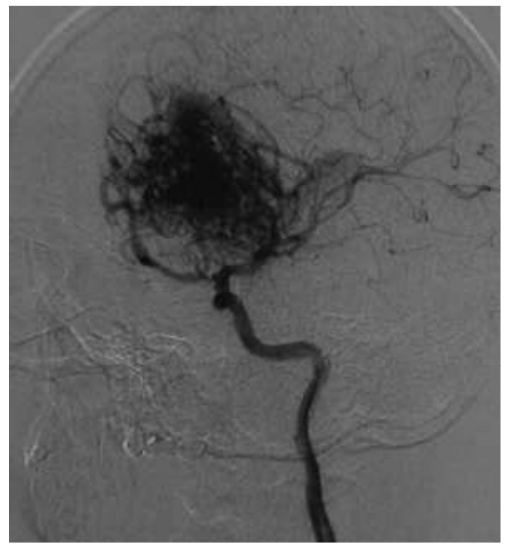

B

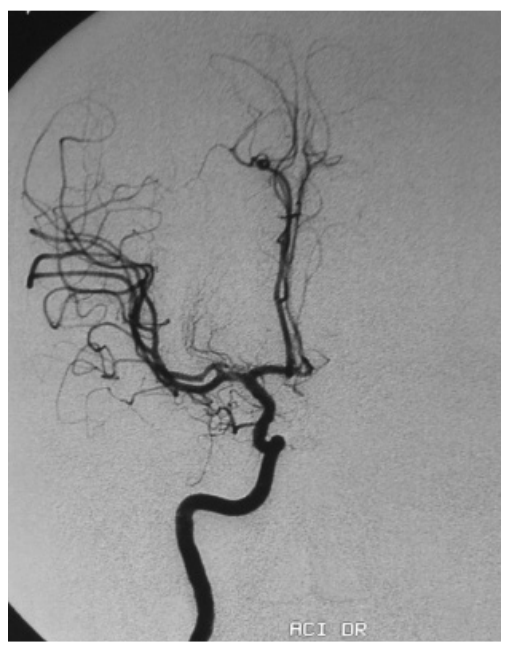

C

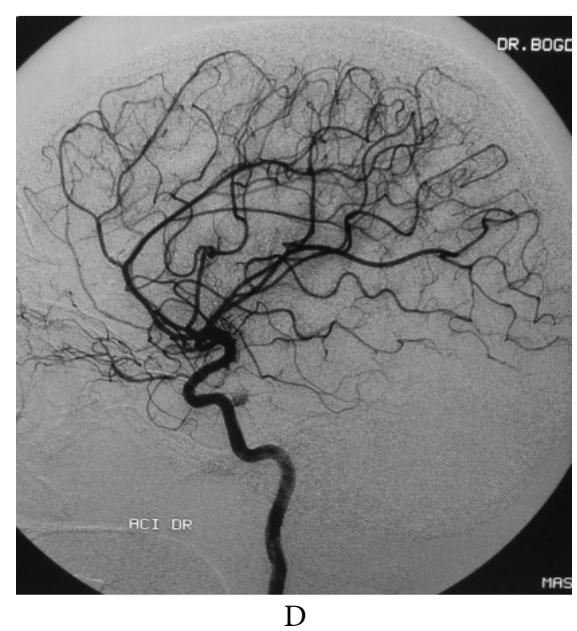

Figure 7 A, B - Right frontal AVM, feeding arteries right ICA, right ECA $(\leftarrow$ STA), left ICA $(\leftarrow$ ACoA $)$ and VBS $(\leftarrow$ PCoA). Multiple enlarged draining veins; C, D - Postoperative aspects: complete resection
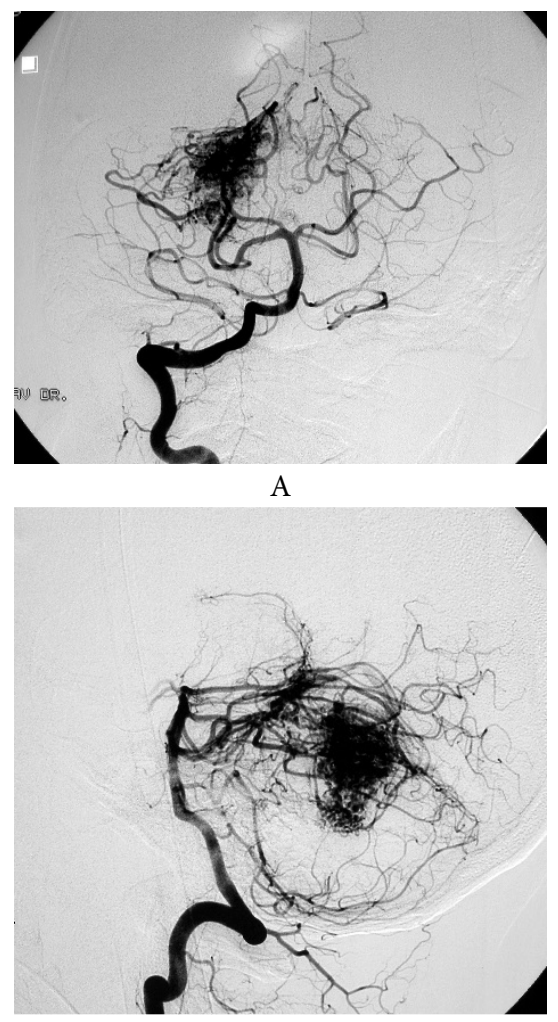

B 
DOI: 10.2478/romneu-2014-0053

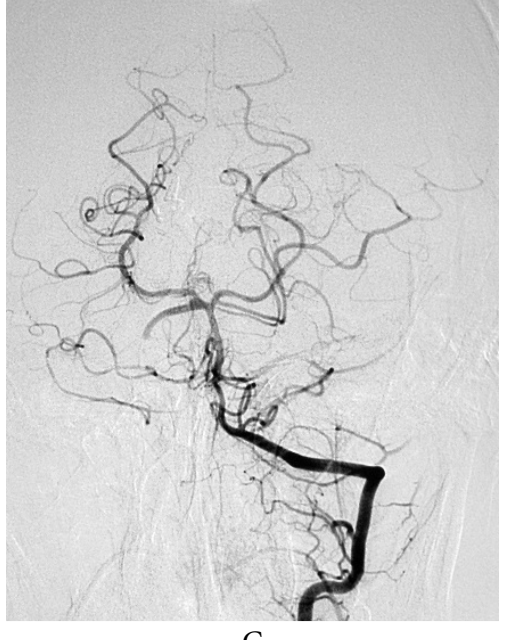

C

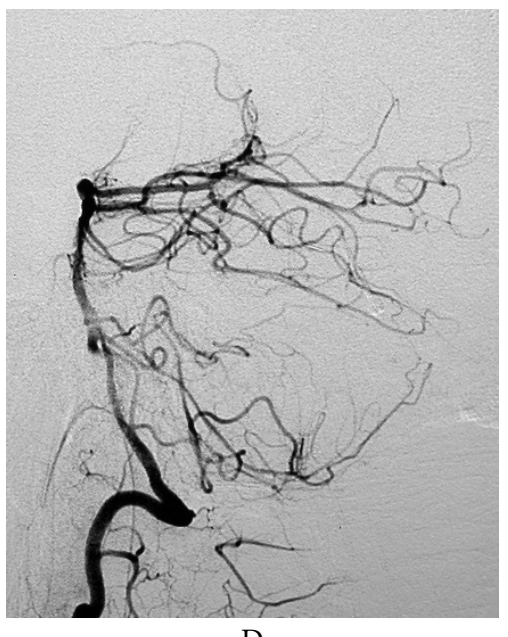

Figure 8 A, B - Infratentorial AVM right cerebellar hemisphere, feeding arteries from SCA and PCA.

Deep venous drainage in Galen vein and superficial in torcular Herophili and lateral sinus;

C, D - Postoperative aspects: complete resection

We used bivariate analysis to see which risk factors for early complications occurrence are. Analyzing clinical data, we found the following risk factors: motor deficit ( $\mathrm{p}=0.006$, $\mathrm{OR}=2.069,95 \%$ CI 1.229-3.482), comorbidities $(\mathrm{p}=0.023, \mathrm{OR}=2.288,95 \%$ CI
1.103-4.744), higher $\mathrm{mRS}(\mathrm{U}=6427.500, \mathrm{p}=$ 0.005), lower Karnofsky score ( $\mathrm{U}=6294.500$, $\mathrm{p}=0.003)$ and lower GCS $(\mathrm{U}=6786.000, \mathrm{p}=$ 0.016). Age, sex, hemorrhage, seizures and altered mental state were not risk factors for developing postoperative complications. Analyzing imaging findings, we found the following risk factors: profound nidus $(\mathrm{p}=$ $0.001, \mathrm{OR}=2.957,95 \%$ CI 1.554-5.625), eloquent aria $(\mathrm{p}=0.000, \mathrm{OR}=3.590,95 \% \mathrm{CI}$ 1.965-6.558), large nidus $(\mathrm{U}=4686.000, \mathrm{p}=$ $0.000)$, multiple arterial territory $(\mathrm{p}=0.000$, $\mathrm{OR}=5.410,95 \%$ CI 3.083-9.492), deep feeding arteries $(\mathrm{p}=0.000$, OR $=4.901,95 \%$ CI 2.736 8.779), higher number of feeding arteries $(\mathrm{U}=$ $2338.000, \mathrm{p}=0.000$ ), deep venous drainage ( $\mathrm{p}$ $=0.000, \mathrm{OR}=5.724,95 \%$ CI 3.278-9.995), multiple draining veins $(\mathrm{p}=0.000, \mathrm{OR}=$ 11.661, 95\% CI 5.799-23.448), higher SpetzlerMartin grade $(U=3006.000, p=0.006)$, high flow $(\mathrm{p}=0.000, \mathrm{OR}=5.050,95 \%$ CI 2.701 9.442), vascular steel $(\mathrm{p}=0.000, \mathrm{OR}=4.945$, 95\% CI 2.842-8.605) and associated aneurysms $(\mathrm{p}=0.010, \mathrm{OR}=2.603,95 \%$ CI 1.233-5.495). Supra/infratentorial location was not a risk factor for developing postoperative complications. Analyzing surgical data we found that decompressive craniectomy was a risk factor $(\mathrm{p}=0.019, \mathrm{OR}=1.955,95 \% \mathrm{CI}$ 1.109-3.446), while total resection/residual nidus were not associated with postoperative complications occurrence.

There were 17 deaths, resulting a mortality rate of $6.1 \%$.

Long-term outcome was favorable and slowly favorable in 241 patients (87.01\%), unfavorable in 15 cases $(5.42 \%)$ and 4 patients $(1.44 \%)$ headed to vegetative state. Patients 
with poor surgical results belonged to the group admitted with severe altered general state and state of consciousness, massive hematomas and acute brainstem dysfunction.

\section{Discussions}

Brain MAVs become clinically manifest and are diagnosed in young people. In our series of patients mean age was 29.82 years. Literature review showed a mean age at onset of 33.7-35 years $(2,13)$. Relevant literature shows either a slight male distribution of the disease (13) or an even gender ratio (2), in our study sex distribution slowly favored men.

AVMs are more likely to present with hemorrhage (3). The rate of hemorrhage is $3 \%$ per year, with initial bleeding rate of $2.2 \%$ per year and rerupture rate of $4.5 \%$ per year (13). In patients with increased risk factors for rupture, such as previous hemorrhage $(16,39)$, exclusively deep venous drainage $(8,16,18,28$, $39)$, large size lesions $(16,40)$ or nidus less than $3 \mathrm{~cm}$ in diameter $(8,21)$, deep $(16,21,39,40)$ and infratentorial locations $(8,16,18,21,29)$, feeders originating in perforating arteries (28), single feeding artery (21), single draining vein (21), combined deep and superficial venous drainage (21), varix of the draining veins (21), associated aneurysms $(18,21)$ and increasing age (39), the hemorrhage rate increases significantly. In our study the majority of patients, $70.40 \%$, presented intracerebral hemorrhage. The most common pattern of bleeding was intraparenchymal hematoma, followed by intraventricular. Less common AVMs bled into the subarachnoid or subdural space. Regardless of bleeding site, hemorrhagic onset is associated with altered mental state and neurological deficits $(19,25)$. Sturiale et al. showed that intraparenchymatal hematoma and intraventricular hemorrhage are associated with severe clinical state at admission. (41) In our series of cases all patients admitted with altered mental state and the majority of patients with motor deficits came from the group with ruptured AVMs.

Seizures were encountered in $31.05 \%$ of cases. Other studies found a seizure rate of $29 \%(10,42)$. Sturiale et al. found predisposal factors for seizure occurrence, such as size $>4$ $\mathrm{cm}$, dilated feeding arteries, cortical location, feeding vessels arising from middle and posterior cerebral arteries (42). Garcin et al. found that masculine sex, large size, location in the frontal lobe, location in the border area of arterial territories, superficial venous drainage, venous ectasia are predictive for occurrence of secondary epilepsy (10). Shankar et al. reported that AVM location, fistulous nidus, venous stenosis, long pial course of draining veins correlated with seizure occurrence (33).

Ideally, complete angioarchitecture of AVMs must be known before surgery. For that, patients with good neurological status are investigated using four or six vessels angiography, the gold standard imaging study. But in some cases, with comatose patients, with ruptured AVMs and life-threatening intracranial hematoma, emergent surgery is required for surgical evacuation of the blood clot. Hemorrhagic presentation is usually ictal, patients, sometimes without history of previous diseases, are admitted with profound altered mental state and new onset 
neurological deficits. In comatose patients CT scan shows intraparenchymatal hematoma, with mass effect, midline shift and cerebral herniation. These patients also present respiratory failure and rapid neurological deterioration. In such cases, the best option is emergent life-saving surgery for hematoma evacuation and decompressive craniectomy, in order to decrease intracranial pressure. After neurological recovery the patient is further investigated for rest of nidus and elective surgery in order to cure the AVM can be performed with good results (30). Superficial, small AVMs can be completely removed at first surgery once hematoma is evacuated, and postoperative angiography shows no abnormal vessels. Patients with good neurological state can be thoroughly investigated before operation and elective surgery is performed.

In a young patient presenting a primary intracranial hematoma the surgeon must always suspect a ruptured AVM, and must be prepared accordingly. The bone flap should be large enough to control a possible AVM. The abnormal dilated vessels on the brain surface draw attention to the possibility of this lesion. After blood clot evacuation the cavity must be inspected for abnormal vessels and the nidus must be resected, in accordance with AVM surgery principles. $(6,11,20,22)$ In spite of poor neurological status, emergent life-saving surgery, with hematoma evacuation and decompressive craniectomy is mandatory, and many patients may experience good neurological recovery $(30,34)$.

Over the time, the outcome of AVM surgery had improved. Morbidity and mortality correlates with Spetzler-Martin grading system. $(31,35)$ Nowadays, low grade AVMs can be safely removed, with low complication rate. Morbidity and mortality increases in higher grades. The higher the grade, the lower is the rate of complete resection. Literature review shows that besides Spetzler-Martin scale, hemorrhagic presentation (19), location (4), eloquent area (31), size $(4,23,31)$, diffuse nidus (7), deep perforanting arteries (7) and deep venous drainage (31) influence the rate of complications and outcome.

In our study 17 patients developed normal perfusion pressure breakthrough. Normal perfusion pressure breakthrough, first described by Spetzler in 1978 (36), characterized by hemorrhage and edema occurring in spite of complete resection of $A V M$, is caused by loss of auto regulation of cerebral vessels from the surrounding brain. The high flow of the AVM steals most of the blood, leaving only a small amount for neighboring areas. Vessels supplying surrounding brain try to compensate the chronic hypoperfusion through vasodilatation and capillary network formation (32). After blood flow redistribution, arterioles cannot constrict, as a consequence of prolong vasodilatation, because they had lost the capacity of autoregulation and capillary break down, leading to hemorrhagic foci and edema. After AVM removal, blood flow is redistributed through dilated arteries to a hypoperfused brain area. Although, the exact pathophysiological mechanism of normal perfusion pressure breakthrough occurrence remains unknown, distant manifestations 
being reported (14). Factors predictive for normal perfusion pressure occurrence are: large size, high flow, vascular steal seen on angiography by paucity of filling with contrast agent of surrounding vessels supplying vicinity brain and filling of the AVM from distant major arteries, feeders from the external carotid artery, clinical vascular steal, objected by fluctuating or progressive neurological deficits (22).

Patients with residual nidus or recurrence can be reoperated or can be referred to Gamma Knife stereotactic radiosurgery. Our policy regarding residual nidus is particular to each case. If residual nidus was found on postoperative angiography and the nidus is located into a surgical suitable area, we preferred second surgery. But residual nidus can originate from AVMs extending into eloquent areas or from particular angioarchitecture, with presence of passing thorough arteries. Passing arteries must be spared because they supply normal brain and their inadvertent occlusion leads to ischemic stroke in distal vascular territories. In cases with nidus surrounding passing through arteries, if you cannot identify and spared the passing through artery, is better to leave a residual nidus. In order to indentify passing through arteries the nidus must be dissected opposite to the arterial supply in order to see which arterial branch passes the tangle of vessels. Passing through arteries usually can be found around middle cerebral artery and pericallosal arteries. We had no recurrence in our series of patients, but it was described in the literature and was associated with young age and deep venous drainage (24).
Flow-related unruptured associated aneurysms remained untouched and control angiography confirmed their disappearance after AVM surgery.

In patients with long-term seizures, surgery allows progressive and significant reducing of doses of antiepileptic drugs.

Social and professional reintegration is extremely important in patients with AVMs, because they are young and active people.

Although available in our hospital, our policy is not to use preoperative embolization, because embolization harbors some week points: it is not a curative treatment, recanalization of the AVM quickly occurs, therefore surgery must be performed within 330 days (12), it can mask arterial feeders, which cannot be seen and secured intraoperatory and may reopen after surgery, it cannot remove the AVM and therefore symptoms secondary to increased intracranial pressure and pseudotumor mass linger, and embolization carries all risks, including rupture, normal perfusion pressure breakthrough, retrograde venous thrombosis, stroke, neurological deficits. Morbidity related to preoperative embolization is $4-8.9 \%$. (4) Yet, advantages of preoperative embolization must not be ignored: it facilitates surgery, decreases intraoperatory blood loss and allows selective embolization $(26,43)$. We used it in 3 patients with residual nidus, with suitable angioarchitecture.

So, our policy in AVMs is surgery first, followed by, in cases with residual nidus, reoperation or stereotactic radiosurgery Gamma Knife. We do not favor endovascular embolization. 
DOI: 10.2478/romneu-2014-0053

\section{Conclusions}

Microsurgery is the treatment of choice for brain AVMs. Surgical results are excellent, there are low morbidity and mortality rates. Motor deficit, co-morbidities, higher mRS, lower Karnofsky score, lower GCS, profound nidus, eloquent aria, large nidus, multiple arterial territory, deep feeding arteries, higher number of feeding arteries, deep venous, multiple draining veins, higher SpetzlerMartin grade, high flow, vascular steel, associated aneurysms and decompressive craniectomy were risk factors for complications occurrence following surgery. Patients with poor surgical results belonged to the group admitted with severe altered general state, state of consciousness, massive hematomas and acute brainstem dysfunction. If for any reason a part of the nidus cannot be safely surgical resected, stereotactic radiosurgery can provide definitive cure of the lesion.

\section{Acknowledgement}

This paper was co-financed from the European Social Fund, through the Sectorial Operational Programme Human Resources Development 2007-2013, project number POSDRU/159/1.5/S/138907 "Excellence in scientific interdisciplinary research, doctoral and postdoctoral, in the economic, social and medical fields - EXCELIS", coordinator The Bucharest University of Economic Studies.

\section{Correspondence}

Aurelia Mihaela Sandu

Emergency Clinical Hospital "Bagdasar-Arseni"

No. 10-12, Berceni Street, Sector 4, Bucharest

E-mail:aurasandu@gmail.com

Tel. 0724.263.023

\section{References}

1. Al-Shahi R, Bhattacharya JJ, Currie DG, Papanastassiou V, Ritchie V, Roberts RC, Sellar RJ, Warlow CP (2003). Prospective, population-based detection of intracranial vascular malformations in adults: the Scottish Intracranial Vascular Malformation Study (SIVMS). Stroke 34, 1163-1169.

2. Al-Shahi R, Warlow C (2001). A systematic review of the frequency and prognosis of arteriovenous malformations of the brain in adults. Brain 124, 19001926.

3. Brown RD Jr, Wiebers DO, Torner JC, O'Fallon WM (1996). Incidence and prevalence of intracranial vascular malformations in Olmsted County, Minnesota, 1965 to 1992. Neurology 46, 949-952.

4. Castel JP, Kantor G (2001). Postoperative morbidity and mortality after microsurgical exclusion of cerebral arteriovenous malformations. Current data and analysis of recent literature. Neurochirurgie 47:369-383.

5. Choi JH, Mohr JP (2005). Brain arteriovenous malformations in adults. Lancet Neurol 2005, 299-308.

6. Deruty R, Turjman F, Pelissou-Guyotat I (2006). Surgical management of cerebral arteriovenous malformations. In Schmidek HH, Roberts DW (Eds.), Operative neurosurgical techniques - indications, methods, and results (pp 1263-1277). Philadelphia, Saunders Elsevier.

7. Du R, Keyoung HM, Dowd CF, Young WL, Lawton MT (2007). The effects of diffuseness and deep perforating artery supply on outcomes after microsurgical resection of brain arteriovenous malformations. Neurosurgery 60, 638-646.

8. Ellis MJ, Armstrong D, Vachhrajani S, Kulkarni AV, DirksPB, Drake JM, Smith ER, Scott RM, Orbach DB (2013). Angioarchitectural features associated with hemorrhagic presentation in pediatric cerebral arteriovenous malformations. J Neurointerv Surg (5), 191-195.

9. Gabriel RA, Kim H, Sidney S, McCulloch CE, Singh V, Johnston SC, Ko NU, Achroff JG, Zaroff JG, Young WL (2010). Ten-year detection rate of brain arteriovenous malformations in a large, multiethnic, defined population. Stroke 41, 21-26.

10. Garcin B, Houdart E, Porcher R, Manchorn E, SaintMaurice JP, Bresson D, Stapf C (2012). Epileptic seizures 
at initial presentation in patients with brain arteriovenous malformation. Neurology 78, 626-631.

11. Gorgan RM (2011). Malformaţiile arteriovenoase cerebrale. In Ciurea AV (Ed.), Tratat de neurochirurgie (pp 117-129). Bucureşti, Editura Medicală.

12. Greenberg MS (2010). Vascular malformations. In Greenberg MS (Ed.), Handbook of neurosurgery. (pp 1098-1142). New York, Thieme Medical Publisher.

13. Gross BA, Du R (2012). Natural history of cerebral arteriovenous malformations: a meta-analysis. J Neurosurg 118, 437-43.

14. Gutierrez-Gonzalez R, Gil A, Serna C, Lopez-Ibor L, Boto GR (2012). Normal perfusion pressure breakthrough phenomenon: what still remains unknown. Br J Neurosurg 26, 403-405.

15. Hartmann A, Mast H, Mohr JP, Koennecke HC, Osipov A, Pile-Spellman J, Duong DH, Young WL (1998). Morbidity of intracranial hemorrhage in patients with cerebral arteriovenous malformation. Stroke 29, 931-934.

16. Hernesniemi JA, Dashti R, Juvela S, Vaart K, Niemela M, Laakso A (2008). Natural history of brain arteriovenous malformations: a long-term follow-up study of risk of hemorrhage in 238 patients. Neurosurgery $63,823-829$.

17. Hillman J (2001). Population-based analysis of arteriovenous malformation treatment. J Neurosurg 95, 633-637.

18. Khaw AV, Mohr JP, Sciacca RR, Schumacher HC, Hartmann A, Pile-Spellman J, Mast H, Stapf C (2004). Association of infratentorial brain arteriovenous malformations with hemorrhage at initial presentation. Stroke 35, 660-663.

19. Lawton MT, Du R, Tran MN, Achrol AS, McCulloch CE, Johnston SC, Quinnine NJ, Young WL (2005). Effect of presenting hemorrhage on outcome after microsurgical resection of brain arteriovenous malformations. Neurosurgery 56, 485-493.

20. Lehecka M, Laakso A, Hernesniemi J (2011): Helsinki microsurgery basics and tricks. Helsinki, Layout: Aesculap AG/D-NE 11002.

21. Lv X, Wu Z, Jinag C, Yang X, Li Y, Sun Y, Zhang N (2011). Angioarchitectural characteristics of brain arteriovenous malformations with and without hemorrhage. World Neurosurg 76, 95-99.

22. Marciano FF, Vishteh AG, Apostolides PJ, Spetzler RF (2000). Arteriovenous malformations - supratentorial. In
Kaye AH, Black P (Eds.), Operative neurosurgery (pp 1079-1091). London, Harcourt Publishers Limited.

23. Morgan MK, Johnston IH, Hallinan JM, Weber NC (1993). Complications of surgery for arteriovenous malformations of the brain. J Neurosurg 78, 176-182.

24. Morgan MK, Patel NJ, Simons M, Ritson EA, Heller GZ (2012). Influence of the combination of patient age and deep venous drainage on brain arteriovenous malformation recurrence after surgery. J Neurosurg 117, 934-941.

25. Munoz F, Clavel P, Molet J, Castano C, de Teresa S, Solivera J, de Quintana C, Tresserras P, Rodriguez R, Bartumeus F (2007). Manejo actual de las malformaciones arteriovenosas. Estudio retrospectivo de 31 casos y revisión de la literatura. Neurocirugia (Astur) $18,394-404$

26. Natarajan SK, Ghodke B, Britz GW, Born DE, Sekhar LN (2008). Multimodality treatment of brain arteriovenous malformations with microsurgery after embolization with onyx: single-center experience and technical nuances. Neurosurgery 62, 1213-1225.

27. Ondra SL, Troupp H, George ED, Scawab K (1990). The natural history of symptomatic arteriovenous malformations of the brain: a 24-year follow-up assessment. J Neurosurg 73, 387-391.

28. Pan J, Feng L, Vinuela F, He H, Wu Z, Zhan R (2013). Angioarchitectural characteristics associated with initial hemorrhagic presentation in supratentorial brain arteriovenous malformations. Eur J Radiol 82, 1959-1963. 29. Rodriguez-Hernandez A, Kim H, Pourmohamad T, Young WL, Lawton MT (2012). Cerebellar arteriovenous malformations: anatomic subtypes, surgical results, and increased predictive accuracy of the supplementary grading system. Neurosurgery 71, 1111-1124.

30. Sandu AM, Gorgan MR (2011). Multimodal treatment for temporobasal arteriovenous malformation - case report. Rom Neurosurg 18, 499-510.

31. Schaller C, Schramm J, Haun D (1998): Significance of factors contributing to surgical complications and to late outcome after elective surgery of cerebral arteriovenous malformations. J Neurol Neurosurg Psychiatry 65, 547-554.

32. Sekhon LHS, Morgan MK, Spence I (1997). Normal perfusion pressure breakthrough: the role of the capillaries. J Neurosurg 86, 519-524.

33. Shankar JJ, Menezes RJ, Pohlmann-Eden B, Wallace C, Terbrugge K, Krings T (2012). Angioarchitecture of 
DOI: 10.2478/romneu-2014-0053

brain AVM determines the presentation with seizures: proposed scoring system. AJNR Am J Neuroradiol 34, 1028-1034.

34. Singhal A, Adirim T, Cochrane D, Steinbok P (2011). Pediatric patients with poor neurological status and arteriovenous malformation hemorrhage: an outcome analysis. J Neurosurg (Pediatrics) 7, 462-467.

35. Spetzler RF, Martin NA (1986). A proposed grading system for arteriovenous malformations. J Neurosurg 65, 476-483.

36. Spetzler RF, Wilson CB, Weinstein P, Mehdorn M, Townsend J, Telles D (1978). Normal perfusion pressure breakthrough theory. Clin Neurosurg 25, 651-672.

37. Stapf C (2010). The rationale behind "A Randomized Trial of Unruptured Brain AVMs" (ARUBA). Acta Neurochir Suppl 107, 83-85.

38. Stapf C, Mast H, Sciacca RR, Berenstein A, Nelson PK, Gobin YP, Pile-Spellman J, Mohr JP (2003). The New York Islands AVM Study: design, study progress, and initial results. Stroke 34, e29-33.

39. Stapf C, Mast H, Sciacca RR, Choi JH, Khaw AV, Connolly ES, Pile-Spellman J, Mohr JP (2006). Predictors of hemorrhage in patients with untreated brain arteriovenous malformation. Neurology 66, 1350-1355. 40. Stefani MA, Porter PJ, terBrugge KG, Montanera W, Willinsky RA, Wallance MC (2002). Large and deep brain arteriovenous malformations are associated with risk of future hemorrhage. Stroke 33, 1220-1224.

41. Sturiale CL, Puca A, Calandrelli R, D'Arringo S, Albanese A, Marchese E, Alexandre A, Colosimo C, Maira G (2013). Relevance of bleeding pattern on clinical appearance and outcome in patients with hemorrhagic brain arteriovenous malformations. J Neurol 324, 118123.

42. Sturiale CL, Rigante L, Puca A, Di Lella G, Albanese A, Marchese E, Di Rocco C, Maira G, Colicchio G (2013). Angioarchitectural features of brain arteriovenous malformations associated with seizures: a single center retrospective series. Eur J Neurol 20, 849-855.

43. Weber W, Kis B, Siekmann R, Jans P, Laumer R, Kuhne D (2007). Preoperative embolization of intracranial arteriovenous malformations with Onyx. Neurosurgery 61, 244-252. 